\title{
Solubility of foraminifera in seawater at high pressures
}

\author{
Ricardo Marcos Pytkowicz and Gerald Allan Fowler \\ Department of Oceanography, Oregon State University, \\ Corvallis, Oregon, U.S.A.
}

(Received September 26, 1967)

\begin{abstract}
In situ $\mathrm{pH}$ electrodes were used to show that solution of pelagic calcareous foraminifera occurs in seawater at pressures between 100 and 1,000 atm. The results confirm earlier work which had indicated that the carbonate compensation depth is not a boundary between super- and undersaturated waters. The degree of solution and hence diagenetic alterations which may affect the geologic record were found to depend on the calcareous species. The results of this work also yielded physicochemical knowledge on the effect of pressure on carbonate icn pairs, on the relative solubilities of calcite and aragonite, and on rates of solution. There is no solubility in the thermodynamic sense but this fact was shown not to affect the value of solubility measurem ents for oceanographic and geochemical work.
\end{abstract}

\section{INTRODUCTION}

Revelle and Fairbridge (1957) and Berner (1965) estimated the effect of pres. sure on the thermodynamic solubility product of calcium carbonate in seawater, and $Z_{E N}$ (1957) estimated this effect on the mole fraction of calcium carbonate present at saturation. These valuable calculations indicated that intermediate and deep oceanic waters are undersaturated with calcium carbonate and stimulated further work. However, these estimates could not be applied quantitatively to the stoichiometry of seawater, because the activity coefficients of carbonate ions as a function of pressure were not known. Disteche and Disteche (1967) have shown that this coefficient should increase with pressure because of the enhanced dissociation of carbonate complexes. Pytkowicz et al. (1967) estimated that only $43 \%$ of the sodium, calcium, and magnesium carbonate ion pairs present at one atm still remain undissociated at 1,000 atm.

Pytkowicz and Connors (1964) measured the pressure coefficient of the apparent (stoichiometric) solubility product of aragonitic oolites with a decompression technique, to avoid using values for the apparent dissociation constants of carbonic acid which needed to be verified. Results, used in conjunction with oceanic $\mathrm{pH}$ and alkalinity data, showed that intermediate and deep oceanic waters are undersaturated (Pyтkowicz, 1965 a). These results were also used to study the role of solution in the carbonate cycle within the oceans (Pytkowicz, 1967). Disteche and Disteche (1967) and Culberson et al. (1967) redetermined the pressure coeffici- 
ents of the apparent dissociation constants of carbonic acid in seawater which permitted solubility determinations for aragonitic oolites at in situ pressures (РуткоWICZ et at. 1967) and the present work with calcitic foraminifera.

Peterson (1966) and Burger (1967) suspended calcite spheres and foraminifera at stations in the North Pacific and, by weight loss, demonstrated that solution occurs at all depths below the first few hundred meters. Our laboratory experiments had yielded similar results; the increase in $\mathrm{pH}$ following exposure of seawater to calcium carbonate in a pressure vessel showed that solution occurs. The depth at which solution should start in the oceans was then obtained by comparing the oceanic ion product $\left(\mathrm{Ca}^{2+}\right)\left(\mathrm{CO}_{3}^{2-}\right)$ with the ion product at saturation (Pyткowicz, 1965 a). Field measurements of weight loss are attractive because of their directness. Laboratory data are valuable because they are economic and fast, and because they permit the determination of the degree of saturation at any field location from simple $\mathrm{pH}$ and alkalinity data that can be obtained during routine hydrographic casts.

The laboratory results in conjunction with oceanic $\mathrm{pH}$ and alkalinity data and the results with suspended particles show that undersaturation exists and that solution occurs at depths much shallower than the compensation depth. These observations indicate that the compensation depth is controlled by rate processes rather than by the degree of saturation.

The laboratory experiments that have been done do not reproduce the dynamic oceanic environment and cannot be used directly for the study of rates of solution in nature, because these rates may depend on the rate of water renewal on the surface of the carbonate particles. The method used by Peterson (1966) and by BuRger (1967) is more direct for rate studies. However, their results so far may have been influenced by the turbulence during the raising and the lowering of the cable which, by fast renewal of water at the surface of the particles, could play a significant role in the observed rate of weight loss. Natural solution occurs in part during the particle settling when the solution rate is controlled by the actual settling rate of calcareous tests which determines the turbulent renewal of water, and in part at the bottom where it is affected by chemical conditions in and near the sediments and by the rate of water stripping by eddy diffusion. Therefore, further work on rates of solution under more natural conditions may provide more accurate answers. In any event, the results of Peterson and Burger illustrate in a dramatic manner the sharp increase in the rate of solution that occurs roughly in the depth range of the compensation depth.

An alternative method to estimate rates of solution was used by Prtkowicz, (1967) who employed oceanic gradients of alkalinity, residence times of deep waters and existing data on river inputs and on rates of sedimentation. This method is indirect and is inherently less accurate than the method of Peterson and Burger but has the advantage of reflecting the results of centuries of solution instead of months. 
The laboratory data until now had been obtained with aragonitic oolites which are only present in special environments such as the Bahama Banks. For this reason we repeated the measurements with pelagic foraminifera which are more representative of calcareous oceanic sediments.

\section{Experimental Procedures}

The artificial seawater used in these experiments was prepared by the method of Kester et al. (1967) and had a salinity of $34.8 \%$. The reference solution consisted of $0.01 \mathrm{~N} \mathrm{HCl}$ brought to the same ionic strength as the seawater by addition of $\mathrm{NaCl}, \mathrm{MgCl}_{2}$ and $\mathrm{CaCl}_{2}$. The cation concentrations were the same in the two electrode compartments. Sulfate was not added to the reference compartment, eliminating the effect of pressure on the dissociation of bisulfate ions which can be sizable at the low $\mathrm{pH}$ of the reference solution (Culberson et al., 1967).

The electrode cell can be represented by

$$
\mathrm{Ag}-\mathrm{AgCl}\left|S W_{i}+\mathrm{CaCO}_{3}\right| \text { Glass membrane } \mid \text { Reference solution } \mid \mathrm{AgCl}-\mathrm{Ag}
$$

and is shown in Fig. 1. This cell was immersed in transmission oil within a pressure bomb. The pressure, generated by a hydraulic pump, was transmitted to the electrode compartment through rubber stoppers. The pressure bomb was jacketed and maintained at $22 \pm 0.03^{\circ} \mathrm{C}$.

The silver-silver chloride electrodes were prepared by coating silver wire electrolytically in a dilute $\mathrm{HCl}$ solution. The glass electrode casing was purchased from Beckman Instruments, Inc. No salt bridge was used with the reference electrodes, thus preventing flow problems at the liquid junction and the need to determine the differential pressure coefficient of the liquid junction potentials. Early determinations of the slope of the pressure electrodes at one atm. were made by determining the $\mathrm{pH}$ of two seawater samples of the same chlorinity with conventional electrodes which had been standardized with two dilute buffers, and then measuring the emf with the pressure electrodes. These determinations were necessary because, in the absence of a salt bridge, a direct calibration of

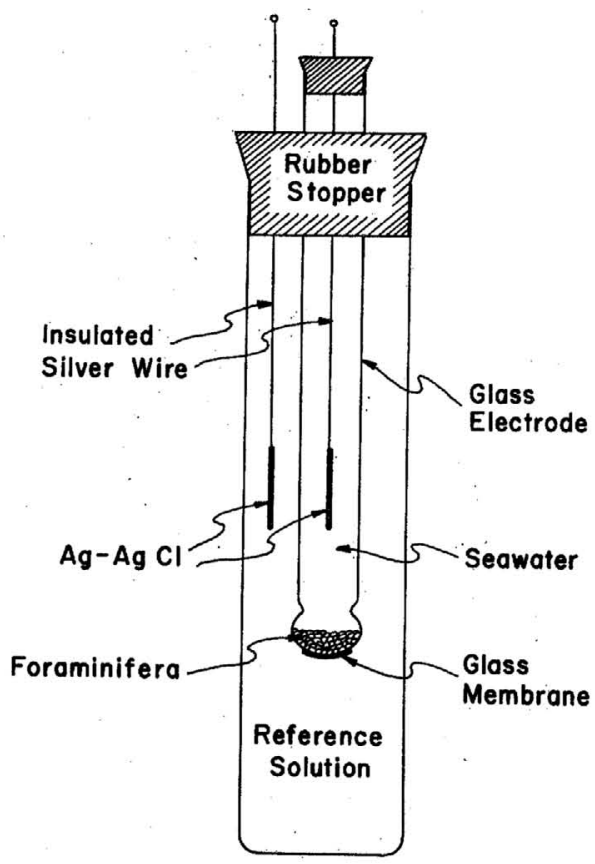

Fig. 1. The high pressure cell. 
the pressure electrodes in dilute buffers was not possible. The slope was found nearly ideal and in subsequent measurements only one buffer was used. pH measurements referred to a dilute buffer scale yield an empirical and operationally defined quantiy $\mathrm{a}_{\mathrm{H}^{+}}$which is obtained from the relation $\mathrm{pH}=-\log \mathrm{a}_{\mathrm{H}^{+}}$. The empirical nature of this quantity does not detract from its usefulness when used in selfconsistent systems in which the same methods are used to determine and to apply equilibrium constants (Pyткоwicz et al., 1966 ).

The emf generated at the electrodes was measured with a potentiometric circuit consisting of a Cary Model $31 \mathrm{CV}$ Vibrating-Reed Electrometer and a Leeds and Northrup Type K3 Potentiometer. The output was monitored on a recorder. This circuit, described in greater detail by KESTER and PyTkowicz (1967), is capable of detecting emf changes that correspond to $\pm 0.0002 \mathrm{pH}$ units. Therefore, it is more sensitive than pH electrodes (Pуткоwicz et al., 1966). The emf at each pressure was followed until a steady state was reached. This required from 6 to $24 \mathrm{hr}$.

The foraminiferal tests used in this study came from a globigerinid ooze at a depth of 4 to $6 \mathrm{~cm}$ in Oregon State University core 6609-20. The core was raised from a water depth of 1,420 fathoms $(2,584 \mathrm{~m})$ at $43^{\circ} 43.3^{\prime} \mathrm{N}, 128^{\circ} 29.0^{\prime} \mathrm{W}$. A sample from 3 to $7 \mathrm{~cm}$ in the core gave a C-14 age of $14,850 \pm 200$ y BP. The composition of the sample before and after the treatment described below is shown in Table 1 . The species of planktonic foraminifera are principally those of BRADSHAw's (1959) sub-arctic fauna with some transition elements.

Table 1. Relative abundance of planktonic foraminifera.

A frequency of less than $1 \%$ is shown as $x$

\begin{tabular}{lcc}
\hline & $\begin{array}{c}\% \text { of Total } \\
\text { Sample }\end{array}$ & $\begin{array}{c}\% \text { of Fraction } \\
<0.250 \mathrm{~mm} \\
0.125 \mathrm{~mm}\end{array}$ \\
\hline Globigerina pachyderma (EHRENBERG) & 38 & 63 \\
Globigerina bulloides d'ORBIGNY & 16 & 14 \\
Globigerina quinqueloba NATLAND & 7 & 7 \\
Globigerina eggeri RHUMBLER & $\times$ & $\times$ \\
Globigerinita uvula (EHRENBERG) & 28 & 2 \\
Globigerinita glutinata (EGGER) & 10 & 14 \\
Globorotalia scitula (BRADY) & $\times$ & $\times$ \\
\hline
\end{tabular}

In order to isolate the planktonic foraminifera tests the sample was first wetsieved on a $63 \mu$ screen. After drying, the residue was put in a beaker of tetrachloroethylene. Most of the hollow, intact foraminiferan tests floated to the surface along with a few radiolarian tests and a small amount of miscellaneous debris. The tests of benthic foraminifera and all non-foraminiferal debris were then hand-picked from the sample leaving a concentrate of pure planktonic foraminiferan tests. This concentrate was then dry-sieved. The fraction between 125 and $150 \mu$ was used for the laboratory experiments. 


\section{Calculation Procedures}

Disteche (1959) showed that $S$, the slope of the glass electrode, is independent of pressure. Therefore $\mathrm{pH}_{\mathrm{p}}$, the $\mathrm{pH}$ at pressure $P$, can be calculated from the expression

$$
\mathrm{pH}_{\mathrm{p}}=\mathrm{pH}_{1}+(1 / S)\left(E_{\mathrm{p}}-E_{1}-\Delta E_{\mathrm{a}}\right) .
$$

$\mathrm{pH}_{1}$ is the $\mathrm{pH}$ of the seawater at equilibrium with the foraminifera at atmospheric pressure. $S$, the electrode slope, was determined as described earlier and $\mathrm{pH}_{1}$ was calculated from $E_{1}$, the emf at one atm. $E_{\mathrm{p}}$ was the observed emf once a steady state was reached at $P$ atm. $\Delta E_{\mathrm{a}}$, the change with pressure in the asymmetry potential of the glass membrane, was measured with reference solution in the two compartments, as was done earlier by Disteche (1959), Disteche and Disteche (1967), and by Culberson et. al. (1967).

Calculations had shown that during equilibration at various pressures the concentrations of calcium and of bicarbonate ions changed only by a few per cent while that of carbonate ions varied by several hundred per cent. The slight change in calcium was limited by its high initial concentration, $10^{-2}$ moles/1 against about $2 \times 10^{-1}$ moles/ 1 for carbonate ions. During solution some carbonate ions react with carbonic acid to form bicarbonate ions. However, the effect of this conversion on the bicarbonate ion concentration was small because the initial bicarbonate ion concentration was about $2 \times 10^{-3}$ moles $/ 1$ while that of carbon dioxide was roughly $2 \times 10^{-5} \mathrm{moles} / 1$. Therefore, the change with pressure in the apparent solubility product can be obtained from the equation

$$
\frac{\left(K_{S P}^{\prime}\right)_{P}}{\left(K_{S P}^{\prime}\right)_{1}}=\frac{\left(\mathrm{a}_{\mathrm{H}^{+}}\right)_{1}}{\left(\mathrm{a}_{\mathrm{H}^{+}}\right)_{P}} \frac{\left(K_{2}^{\prime}\right)_{P}}{\left(K_{2}^{\prime}\right)_{1}} .
$$

$K_{S P}^{\prime}=\left(\mathrm{Ca}^{2+}\right)\left(\mathrm{CO}_{3}^{2-}\right)$ is the apparent (stoichiometric) solubility product, that is, the product of the ionic concentrations at saturation. $\mathrm{a}_{\mathrm{H}^{+}}$is the hydrogen ion activity referred to a dilute buffer scale. $K_{2}^{\prime}=\mathrm{a}_{\mathrm{H}}+\left(\mathrm{CO}_{3}^{2-}\right) /\left(\mathrm{HCO}_{3}^{-}\right)$is the second apparent dissociation constant of carbonic acid in seawater. The change with pressure in the activity of hydrogen ions was obtained from equation 2 and from the measured emf after a steady state was reached.

Apparent equilibrium constants are used in this work because, as the activity coefficients of the various carbonate species depend on ion pair formation and cannot be estimated from ionic strength considerations alone, thermodynamic constants cannot be applied to the stoichiometry of seawater. This situation may change when activity coefficients become known as a function of temperature, pressure, and salinity. However, the use of thermodynamic constants will not be important even then, because thermodynamic constants used in conjuction with activity co. efficients are equivalent to and can be replaced by apparent constants. These considerations do not apply to the hydrogen ion activity for reasons stated earlier. 
One could define apparent dissociation constants by using hydrogen ion concentrations (Dyrssen and Sillen, 1967) but this is not strictly necessary because errors introduced by the arbitrarity in $\mathrm{pH}$ are cancelled, within the reproducibility of $\mathrm{pH}$ measurements, between the determination and the application of the equilibrium constants (Pyткоwicz et al., 1966). Degrees of saturation can be determined by comparing ion products to the apparent solubility products or by determining the number of moles of solid that must dissolve or precipitate to ensure saturation (Pyтkowicz, 1965 a). The use of apparent solubility products is more convenient because these products do not depend on the carbon dioxide content of the seawater.

The pressure coefficient of $K_{2}^{\prime}$ was obtained by the method of Culberson et al. (1967), with measurements extended to 1,000 atm. As the effect of sulfate in the reference compartment is cancelled out, the pressure coefficients of the activity of chloride ions may not be exactly the same in the two electrode compartments. The resulting error is probably small but in any event it can be incorporated into the definition of $\mathrm{pH}$ and consequently of equilibrium constants at pressure. Then, the resulting effect cancels out between the determination and the application of the constants if the same methods are used for the two types of measurements.

The degree of undersaturation at any time and pressure was expressed as $I P / K_{S P}^{\prime}$, where $I P$ is the ion product $\left(\mathrm{Ca}^{2+}\right)\left(\mathrm{CO}_{3}^{2-}\right)$ at that time and pressure and $K_{S P}^{\prime}$ is the ion product once a steady state is reached. As the calcium and the bicarbonate ion concentrations remained fairly constant during the experiments, this ratio was calculated from the equation

$$
\frac{I P}{K_{s P}^{\prime}}=\frac{\left(\mathrm{CO}_{3}^{2-}\right)}{\left(\mathrm{CO}_{3}^{2-}\right)_{s}}=\frac{\left(\mathrm{a}_{\mathrm{H}^{+}}\right)_{s}}{\left(\mathrm{a}_{\mathrm{H}^{+}}\right)}
$$

The subscript $S$ refers to values at the steady state.

\section{Results AND Discussion}

The transient behavior of the emf during compression is shown in Fig. 2. The increase in emf with time at each pressure corresponds to an increase in $\mathrm{pH}$ which results from solution of calcium carbonate. There also is a very fast acidification that results from the change in the apparent dissociation constants upon pressure increase. This acidification, which is soon overshadowed by carbonate solution, is not shown in Fig. 2 because it is too fast for the time scale employed. Our equipment does not hold the pressure overnight at $100 \mathrm{~atm}$ and the observed emf drop may be due to a decrease in pressure. The maximum value reached by the emf was selected as representing the steady state value. This selection is arbitrary but does not appear to introduce a serious error because the 100 atm value of $\log \left(K_{S P}^{\prime}\right)_{P} /\left(K_{S P}^{\prime}\right)_{1}$ fell on a linear plot of this quantity $v s$. pressure. Such a linear relation is expected from the exponential dependence of the pressure coefficient of the apparent solubility product on the pressure. This relation was 


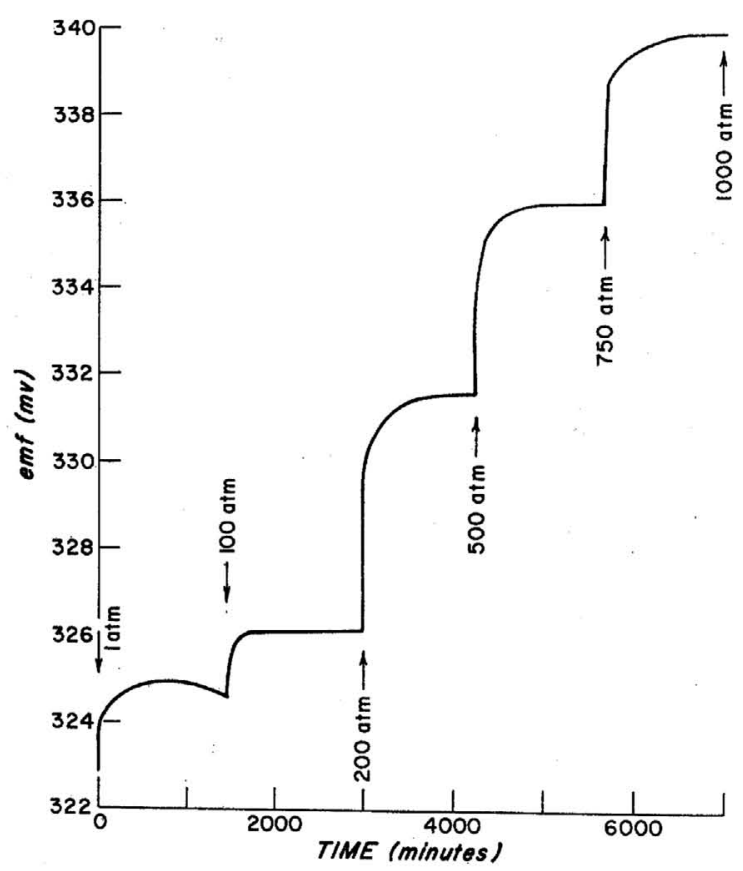

Fig. 2. Observed emf vs. time for pelagic calcitic foraminifera in seawater of $34.8 \%$ salinity at $22^{\circ} \mathrm{C}$ and at various pressures.

Table 2. The pressure coefficients of the apparent (stoichiometric) solubility products of calcitic foraminifera and of aragonitic oolites in seawater at $25^{\circ} \mathrm{C}$ as a function of pressure

\begin{tabular}{ccc}
\hline \hline Pressure (atmospheres) & Foraminifera & Oolites \\
\hline 1 & 1.00 & 1.00 \\
100 & 1.10 & \\
200 & 1.25 & \\
500 & 1.88 & 1.79 \\
750 & 2.62 & 3.18 \\
1,000 & 3.56 & 1.82 \\
500 & 2.12 & 1.22 \\
1 & 1.18 &
\end{tabular}

roughly followed at $200,500,750$ and 1,000 atm.

The pressure coefficients for the apparent solubility product of calcitic foraminifera for sea water of $34.8 \%$ salinity at $22^{\circ} \mathrm{C}$ are presented in Table 2 . The values in the third column are a modification of those obtained earlier for aragonitic oolites (Pytkowicz et al., 1967). The earlier values were obtained with a cell that contained sulfate in the reference compartment, and are valid in a system in which that type of cell is always used. However, the earlier values had to be corrected 
for the effect of the dissociation of bisulfate ions before they could be compared to our present results for calcitic foraminifera. The correction was obtained from the emf generated between two reference solutions of the same ionic strength, only one of which contained sulfate ions.

During pressure release the $\mathrm{pH}$ underwent a minimum at each pressure before reaching a steady state value. The steady state value was higher than that obtained at the same pressure during compression. The main difference between the two sets of runs is that during pressure buildup the steady state value was approached from undersaturation while during decompression it was approached from supersaturation. Thus, precipitation occurs during decompression. This precipitation probably occurs on the surface of the foraminifera because, as was shown by Pyтkowicz (1965 b), precipitation of calcium carbonate fron supersaturated solutions requires an extremely long time in the absence of nucleating surfaces. The high values of the steady state $\mathrm{pH}$ and the minimum values of the $\mathrm{pH}$ that occur during the equilibration runs after pressure release indicate that, during precipitation, a calcium carbonate phase is formed which is more soluble than that which was present originally on the surface of the foraminifera.

A similar observation was made with aragonitic oolites for which the minimum was found to be related to the presence of magnesium ions in seawater (PуткоwICz et al., 1967). It is conceivable that there is a gradual enrichment in magnesium at the surface of the solid phase, either through direct ion exchange (BERNER, 1966) or through a slow replacement by a calcium carbonate phase with a higher magnesium content than that formed at the beginning of the saturation runs. The hysteresis upon compression and decompression suggests that a classical solubility which is reversible to slight excursions into under- or supersaturation does not appear to occur in the foraminifera experiments. However, McINTYRE (1965) found a reversible solubility, that is equilibrium, for calcite and aragonite powders in seawater and our earlier measurements with oolites did not show hysteresis upon compression and decompression. Therefore, lack of reversibility is not necessarily a general feature of solubility measurements in seawater. The absence of a solubility in the thermodynamic sense does not detract from the value of $\left(K_{S P}^{\prime}\right)_{P} /$ $\left(K_{S P}^{\prime}\right)_{1}$, determined during compression, for oceanographic interpretations. Foraminifera only sink, that is, they undergo compression in the oceans and we are interested in knowing at what depth they start dissolving and what the degree of saturation of the waters is. The values during decompression are of interest to study the meaning of solubilities in seawater but do not represent a condition that occurs in the recent oceans. The increase in $\mathrm{pH}$ with time at pressure shows that the tests dissolve until a steady state, of an unknown nature, is reached. It will be of interest to make similar measurements on samples of pelagic foraminifera obtained from shallow environments because our samples already underwent one pressure cycle before the laboratory measurements.

The pressure coefficients of the apparent solubility product of calcitic forami- 
nifera during pressure increase are even larger than those for aragonitic oolites. This fact shows that earlier conclusions, based on the solubility of oolites (PyTkowicz and Connors, 1964; Pytkowicz, $1965 \mathrm{a}, 1967$; Pytkowicz et al., 1967) which showed that the oceans are undersaturated at depths below the first few hundred meters, are reinforced by the present data. Calcitic foraminifera are more representative of the calcareous species found in oceanic sediments than oolites.

Our pressure data for calcitic foraminifera, combined with the apparent solubility products for calcite at one atm (MAcINTYRE, 1965), yielded the apparent solubility products at in situ pressures, temperatures, and salinities which are shown in the second column of Table 3 . The pressure coefficient of the apparent solubility product is only known at $22^{\circ} \mathrm{C}$ and we are determining it at lower temperatures. However, the temperature effect is probably slight (Pytkowicz and Connors, 1964). It is likely that the data of MAcINTYRE applies to our samples because his formula yields a solubility product of $5.6 \times 10^{-7}$ at $22^{\circ} \mathrm{C}$ and $34.8 \%$ salinity and we found that the solubility product of our foraminiferal sample was approximately $5 \times 10^{-7}$ under the same conditions.

Table 3. Apparent solubility products, observed ion products, and degree of saturation at $50^{\circ} 27.5^{\prime} \mathrm{N}$ and $176^{\circ} 13.8^{\prime} \mathrm{W}$. Field data obtained aboard the R. V. Yaquina during Yaloc 66, at station HAH-56 on June 22, 1966 by K. PARK

\begin{tabular}{cccc}
\hline Depth (meters) & $K_{S P}^{\prime} \times 10^{7}$ & Ion product $\times 10^{7}$ & $\begin{array}{c}\text { Per cent } \\
\text { saturation }\end{array}$ \\
\hline 0 & 6.2 & 13.8 & 230 \\
190 & 6.7 & 4.1 & 61 \\
468 & 7.1 & 4.4 & 62 \\
753 & 7.4 & 4.4 & 59 \\
1,425 & 8.2 & 5.9 & 72 \\
2,262 & 9.2 & 6.8 & 74 \\
3,256 & 10.4 & 8.7 & 84 \\
4,499 & 12.2 & 8.9 & 73 \\
7,210 & 17.3 & 9.6 & 55 \\
\hline
\end{tabular}

The third column of Table 3 shows the ion products calculated from $\mathrm{pH}$ and alkalinity data obtained by $\mathrm{K}$. PARK aboard the R. V. Yaquina at station HAH-56 of Yaloc 66. The field data was obtained on June 22,1966 at $50^{\circ} 27.5^{\prime} \mathrm{N}$ and $176^{\circ}$ $13.8^{\prime} \mathrm{W}$. The ion products at in situ conditions were calculated using pressure coefficients of the apparent dissociation constants of carbonic and boric acids determined by C. Culberson in our laboratory, and Lxman's (1956) values of these constants at one atm. Culberson's results are an extension of those of Culberson et al. (1967) to lower temperatures and higher pressures and will be presented for publication in the near future. The data in the fourth column is the degree of saturation.

These results confirm earlier conclusions (PytKowicz and Connors, 1964; Berner, 1965; Pỵtkowicz, 1965a, 1967; Pețersonon, 1966; Bụrger, 1967) that the oceans are 
undersaturated at depths below the first few hundred meters. LI (1967) reached a different conclusion and stated that the oceans are saturated down to the compensation depth. However, our earlier and present data, in contrast to that of Lr, show a well defined minimum degree of saturation at the oxygen minimum level. This is expected because the high partial pressure of carbon dioxide generated by oxidation significantly lowers the $\mathrm{pH}$, as was shown in the North Pacific Ocean by PARK (1966). It is surprising that LI's calculated $\mathrm{pH}$ values and degrees of saturation either do not show this major feature of the oceans, or show it in a very attenuated form.

These results suggest that the compensation depth is the result of rate effects. The nature of these rate effects is unknown but one may speculate that they are related to a greater eddy diffusion in waters deeper than the compensation depth. Such enhanced eddy diffusion would cause a faster renewal of the water layer at the surface of the calcareous tests and thus would increase the rate of solution of the tests. This enhanced diffusion would also increase the supply of carbon dioxide needed for the dissolution of calcium carbonate.

The results obtained for calcitic foraminifera are not necessarily general and further work is necessary to characterize the behavior of various calcareous species with pressure. Pyткоwicz, Disteche and Disteche (unpublished results) observed that aragonitic mollusc fragments in artificial seawater dissolved for the first few hours after pressure increase. However, this solution was followed by precipitation. The experiments were not carried on for long enough times to ascertain whether there was net solution as a result of pressure increase.

The calcitic foraminifera used in this work were examined before and after pressurization. There was a noticeable increase in the solution effects visible on the exterior of the foraminiferal tests. Prior to treatment $6 \%$ of the tests showed signs of solution. At the conclusion of the experiment $13 \%$ showed similar signs. Globigerina pachyderma, G. quinqueloba, and Globigerinita glutinata demonstrated the greatest increase in solution effects.

The pressure coefficient of the apparent solubility product $\left(K_{S P}^{\prime}\right)_{P} /\left(K_{S P}^{\prime}\right)_{1}$ is smaller than that of the thermodynamic solubility product $\left(K_{S P}\right)_{P} /\left(K_{S P}\right)_{1}$ which was estimated at $25^{\circ} \mathrm{C}$ by Revelle and Fairbridge (1957) from the partial molar volume data of OwEN and BRINkLEY (1941). This is understandable because

$$
\frac{\left(K_{S P}^{\prime}\right)_{P}}{\left(K_{S P}^{\prime}\right)_{1}}=\frac{\left(K_{S P}\right)_{P}}{\left(K_{S P}\right)_{1}} \frac{\left(f_{\left.\mathrm{CO}_{3}^{2}-\right)_{1}}\right.}{\left(\mathrm{f}_{\left.\mathrm{CO}_{3}^{2}-\right)_{P}}\right.}
$$

where $\mathrm{f}_{\mathrm{CO}}{ }^{2-}$ is the activity coefficient of carbonate ions. The activity coefficient of calcium ions does not appear in this expression because it is almost constant as a result of the high concentration of calcium ions. The activity coefficient of carbonate ions increases with pressure because, according to Disteche and Disteche (1967) and to Pytrowicz et al. (1967), the $\mathrm{NaCO}_{3}^{-}, \mathrm{CaCO}_{3}^{\circ}$, and $\mathrm{MgCO}_{3}^{\circ}$ ion pairs dissociate with increasing pressure, 
Equation 5 can be used to estimate roughly the change in the activity coefficient of carbonate ions if the data in Table 2 and that of REvelle and FaIRBridge (1957) are entered into that equation. The value of $\left(\mathrm{f}_{\mathrm{CO}_{3}^{2-}}\right)_{1} /\left(\mathrm{f}_{\mathrm{CO}_{3}^{2-}}\right)_{P}$ went from 1 at atmospheric pressure to 0.73 at 500 atm and to 0.53 at 1,000 atm. This change shows that the concentration of free carbonate ions at atmospheric pressure is $73 \%$ and $53 \%$ of the concentrations of free carbonate ions present at 500 and 1,000 atm, respectively. The extent of dissociation of carbonate ion pairs will depend on the concentration of the ion pairs at atmospheric pressure. If the data of Garress and THOMpson (1962) at atmospheric pressure is used, then $4 \%$ and $9 \%$ of the carbonate ion pairs present at one atm will dissociate at 500 and 1,000 atm. This determination is not exact because to some extent the difference between our values and those of REvelLE and FAIRBRIDGE may also be due to the different specific volumes of pure calcite and of magnesium calcites found in foraminifera, to a possible change with pressure in the composition of the surface of the foraminifera, and to the slight temperature difference between the two sets of results. These effects, however, should not be large. Since our results do not include the temperature dependence of the solubility, we cannot compare them to the thermodynamic estimates of BERNER (1965).

The pressure coefficients of the solubility products of calcite were larger than those for aragonites, both in our experiments and in the estimates of REvELLE and FAIRBRIDGE (1957). At 1,000 atm we found that the ratio of the pressure coefficients of the apparent solubility products of calcite and of aragonite was 1.12. The same value is obtained from the thermodynamic solubility products estimated by REvelLE and FAIRBRIDGE (1957).

As was mentioned earlier, a plot of $\log \left(K_{s P}^{\prime}\right)_{P} /\left(K_{s P}^{\prime}\right)_{1} v s$. pressure was linear showing that a general expression of the type

$$
\left(K_{S P}^{\prime}\right)_{P} /\left(K_{S P}^{\prime}\right)_{1}=\exp \frac{1}{R T} \int_{1}^{P} \Delta \bar{v} d P
$$

holds. This expression is of the type found for pressure coefficients of thermodynamic solubility products. However, $\Delta \bar{v}$ is not simply the change in partial molar volume due to the ionization of calcium carbonate because the dissociation of ion pairs must also be considered.

The values of $I P / K_{s I}^{\prime}$, which express the degree of saturation at time $t$ after pressurization are shown in Fig. 3. Only the time range between 3 and 150 min is shown because beyond $150 \mathrm{~min}$ the slopes are too slight and in the first $3 \mathrm{~min}$ they are too steep for precise determinations. The curve at $100 \mathrm{~atm}$ was roughly similar to that at 200 atm but could not be adequately plotted because of the ambiguity in the steady state value. It is seen from the slopes of the curves that, for a given degree of saturation, the rate of solution decreases in going from 200 to $500 \mathrm{~atm}$ and then remains constant with pressures up to $1,000 \mathrm{~atm}$. This can be seen quantitatively by comparing the values of the slopes $d\left(I P / K_{S P}^{\prime}\right) / d t$ at a given value of $I P / K_{S P}^{\prime}$ for the various pressures. The value of this rate of approach 


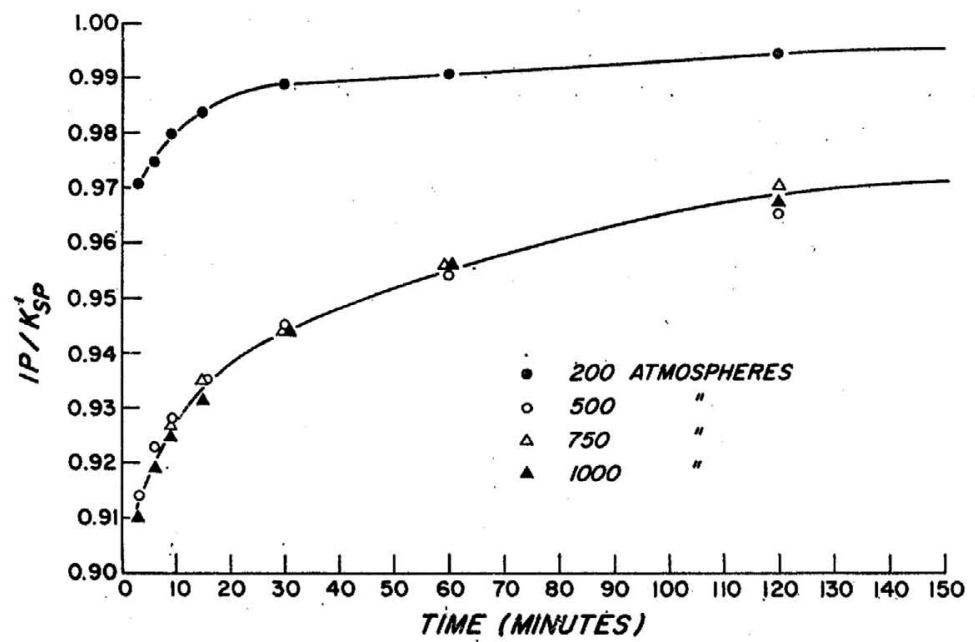

Fig. 3. Values of $I P /\left(K_{S P}^{\prime}\right)$ vs. time at 200. 500, 750 and 1,000 atm.

to saturation, for $I P / K_{s P}^{\prime}=0.97$, was about $0.2 \% / \mathrm{min}$ at $200 \mathrm{~atm}$ and $0.004 \% / \mathrm{min}$ at 500,750 and 1,000 atm. This decrease in the rate of solution with increasing pressure cannot be adequately explained at present. It may be due in part to the slower diffusion resulting from the increased viscosity of seawater at high pressures. However, this increase in viscosity is slight and could not justify a 50 -fold decrease in the rate of approach to saturation.

Our system was quiescent and is similar to that encountered in the interstitial waters of sediments. However, it neither reproduces conditions at the sedimentwater interface nor conditions during particle settling when most oceanic solution of calcareous particles probably occurs. Therefore, our observed rates, although of interest from a chemical point of view, cannot be used to study the geochemical cycle of carbonates in the oceans and the compensation depth. The rate observations of Peterson (1966) and of Burger (1967) and the calculations of Pytkowicz (1967) are more pertinent to the oceanic situation.

Thus, it has been amply shown by several authors and in this work that the oceans are undersaturated with calcium carbonate at all depths below the first few hundred meters. However, the compensation depth has not yet been adequately explained. Also, it is seen from our results that the degree of solution at high pressures varies with the calcareous species. This effect requires further study so that we may better understand diagenetic alterations that may affect the geologic record in deep oceanic sediments. This work also has yielded physico-chemical knowledge such as the effect of pressure on the degree of complexing of carbonate ions in seawater, the differential solubility of calcite and aragonite as a function of pressure, the absence of an equilibrium solubility in the thermodynamic sense which does not detract from the value of solubility measurements for oceanographic and 
geochemical work, and the effect of pressure on rates of solution which requires further study.

\section{Acknowledgements}

This work was supported by the National Science Foundation Grant GA-301. The authors thank Mr. C. Culberson for his assistance with the high pressure measurements, and Professor KILHo PARK who made his $\mathrm{pH}$ and alkalinity data available to us.

\section{REFERENCES}

BERNER, R. A. (1965) Activity coefficients of bicarbonate, carbonate, and calcium ions in sea water. Geochim. Cosmochim. Acta 29, 947-965.

BERNER, R. A. (1966) Diagenesis of carbonate sediments: Interaction of magnesium in sea water with mineral grains. Science 153, 188-191.

BRADSHAW, J. S. (1959) Ecology of living planktonic foraminifera in the north and equatorial Pacific Ocean. Contr. Cushman Found. Foram. Research 10, 25-64.

BURgER, W. H. (1967) Foraminiferal ooze. Solution at depths. Science 156, 383-385.

CUlberson, C., Kester, D. R. and PyTKowicz, R. M. (1967) High pressure dissociation of carbonic and boric acids in seawater. ibid. 157, 59-61.

DISTECHE, A. (1959) $\mathrm{pH}$ measurements with a glass electrode withstanding $1,500 \mathrm{~kg} / \mathrm{cm}^{2} \mathrm{hy}$. drostatic pressure. Rev. Scient. Instrum. 30, 474-478.

DISTECHE, A. and DISTECHE, S. (1967) The effect of pressure on the dissociation of carbonic acid from measurements with buffered glass electrode cells. J. Electrochem. Soc. 114, 330340 .

DYRSSEN, D. and SILLEN, L. G. (1967) Alkalinity and total carbonate in sea water. Tellus 19, $112-120$.

GARRels, R. M. and Thompson, M. E. (1962) A chemical model for sea water at $25^{\circ} \mathrm{C}$ and one atmosphere total pressure. Am. J. Sci. 260, 57-66.

KeSter, D. R., Duedall, I. W., ConNoRs, D. N. and PytKowicz, R. M. (1967) Preparation of artificial seawater. Limnol. Oceanogr. 12, 176-179.

KESTER, D. R. and PYTKOwICZ, R. M. (1967) Determination of the apparent dissociation constants of phosphoric acid in seawater. ibid. $12(2), 243-252$.

L.I, H. L. (1967) The degree of saturation of $\mathrm{CaCO}_{3}$ in the oceans. Ph. D. Thesis. Columbia University, New York.

LYMAN, J. (1956) Buffer mechanism of sea water. Ph. D. thesis. University of California, Los Angeles.

MCINTYRE, W, G. (1965) The temperature variation of the solubility product of calcium carbonate in sea water. Fish. Res. Bd. of Canada, Manuscript Rep. Ser. 200, Ottawa, Canada.

OWEN, B. B. and BRINKLEY, S. R. (1941) Calculation of the effect of pressure upon ionic equilibria in pure water and in salt solutions. Chem. Rev. 29, 461-474.

PARK, K. (1966) Deep-sea pH. Science 154, 1540-1542.

PETERSON, M. N. A. (1966) Calcite: Rates of dissolution in a vertical profile in the Central Pacific. ibid. 154, 1542-1544.

PYTKOwICZ, R. M. (1965 a) Calcium carbonate saturation in the ocean. Limnol. Oceanogr. 10, $220-225$.

Pytkowicz, R. M. (1965 b) Rates of inorganic calcium carbonate nucleation. J. Geol. 73, 196166.

Pytkowicz, R. M. (1967) Carbonate cycle and the buffer mechanism of recent oceans. Geo- 
chim. Cosmochim. Acta 31, 63-73.

PytKowicz, R. M. and ConNoRs, D. N. (1964) High pressure solubility of calcium carbonate in sea water. Science 144, 840-841.

PytKowicz, R. M., KeSter, D. R. and Burgener, B. C. (1966) Reproducibility of pH measurements in seawater. I imnol. Oceanogr. 11, 417-419.

Pytkowicz, R. M., Disteche, A. and Disteche, S. (1967) Calcium carbonate solubility in seawater at in situ pressures. Earth Planet. Sci. Letters. 2, 430-432.

REVElLE, R. and FAIRBRIDGE, R. (1957) Carbonates and carbon dioxide. Treatise on Marine Ecology and Paleoecology 1, 239-295. Geol. Soc. Am., New York.

ZEN, E-AN (1957) Partial molar volumes of some salts in aqueous solutions. Geochim. Cosmo. chim. Acta 12, 103-122. 